\title{
Systematic Position of Gluconobacter liquefaciens
}

\author{
By M. R. KIMMITT \\ H.P. Sauce Ltd., Aston Cross, Birmingham 6 \\ AND P. J. LE B. WILLIAMS \\ Department of Biochemistry, University of Birmingham
}

(Received 17 October 1962)

\begin{abstract}
SUMMARY
A strain of Gluconobacter liquefaciens was found to possess peritrichous flagella. Because of this and its biochemical similarity to Acetobacter aceti, the organism should be transferred to the genus Acetobacter as restricted by Leifson.
\end{abstract}

\section{INTRODUCTION}

Taxonomists prefer to divide the acetic acid bacteria, i.e. the genus Acetobacter as used by Beijerinck, into two genera. The organisms of one genus, Acetobacter, as restricted by Leifson, characteristically oxidize ethanol to carbon dioxide and water, via acetic acid; these organisms, when motile, possess peritrichous flagella. The other genus, Acetomonas Leifson (syn. Gluconobacter Asai), comprises those organisms which oxidize ethanol to acetic acid and no further (the suboxydans group of Frateur's 1950 classification) and which, when motile, possess polar flagella. The evidence for this division, on the basis of a correlation between type of flagellation and biochemical properties, may be seen in the papers of Leifson (1954) and Shimwell (1958). The position regarding the classification of these organisms has recently been reviewed by Carr \& Shimwell (1961).

Gluconobacter liquefaciens Asai (1934) is one of three organisms reported by Asai \& Shoda (1958) as possessing polar flagella and the ability to oxidize lactate and acetate to carbonate- a combination of characters intermediate between Acetobacter and Acetomonas as defined above. (Asai \& Shoda used the generic name Gluconobacter as an approximate synonym for Acetomonas on the basis of earlier work by Asai, but it does not appear to have been either accurately defined or validly published.) The other two organisms were examined by Shimwell \& Carr (1959) and found to possess not polar but peritrichous flagella. Stouthamer (1960) reported G. liquefaciens to possess peritrichous flagella but his photograph did not convince De Ley (1961). The organism has been used in several studies (De Ley \& Dochy, 1960; De Ley, 1961; Stouthamer, 1961, 1962), in at least one of which (Joubert, Bayens \& De Ley, 1961), its position appears to be anomalous. If indeed the flagellation is polar, the classification into Acetobacter and Acetomonas might be questioned. It seemed worth while to re-examine $G$. liquefaciens to see whether it possesses polar flagella, as reported by Asai \& Shoda, or peritrichous flagella, as reported by Stouthamer. If it is in fact polarly flagellate it is intermediate between Acetomonas and Acetobacter and its existence would put in question the value of Leifson's (1954) classification of the acetic acid bacteria. 


\section{METHODS}

Organism. A culture of the Gluconobacter liquefaciens strain studied by Asai (De Ley, 1961) was obtained from the laboratory of Professor De Ley through the kindness of Dr J. Schell. The culture was classified biochemically by using the scheme and methods of Frateur (1950).

Examination for flagella. Samples were prepared for examination in the light microscope by using Gray's flagella stain and for the electron microscope by shadowing with gold + palladium and viewing in an A.E.I. Electron Microscope EM6.

\section{RESULTS}

The organism examined was a Gram-negative rod showing a moderate degree of pleomorphism. It oxidized ethanol to acetic acid and thence to carbon dioxide and water. 'Irisation' was produced when the organism was grown on agar plates of Difco yeast extract + calcium lactate. It grew in Hoyer's medium, was catalase positive, produced acid from glucose and dihydroxyacetone from glycerol (ketogenic ability). The organism also produced a brown-black pigment when grown on agar slopes of Difco yeast extract + glucose $+\mathrm{CaCO}_{3}$.

Visual and electron microscopy showed clearly the organism to possess peritrichous flagella; two of the electron micrographs are shown in the plate.

\section{DISCUSSION}

This work shows that the strain of Gluconobacter liquefaciens examined possesses both peritrichous flagella and the ability to oxidize ethanol beyond acetate, and it clearly belongs to the genus Acetobacter as restricted by Leifson. According to Frateur's classification it would be placed in the species $A$. aceti. However, it differs from $A$. aceti as defined by Frateur in producing a brown-black pigment, when grown on glucose $+\mathrm{CaCO}_{3}$. The production of a pigment is characteristic of some Acetomonas strains. What taxonomic significance should be given to pigment formation is not known. There have been other reports of acetobacters (as defined above) as possessing polar flagella; but those which have been investigated have, as in the present case, been found to be incorrect. It is perhaps significant that there have been no reports of acetomonads which possess peritrichous flagella. The explanation might be that the rather few lateral flagella of Acetobacter may easily become detached and so convert a peritrichously flagellate organism into one which appears to be polarly flagellate. Although the possibility that an organism might possess both polar flagella and the ability to oxidize alcohol to completion cannot be ruled out, no such organism is known.

We are greatly indebted to Mr C. C. Newton of the Department of Electron Physics, University of Birmingham, for his technical assistance. One of the authors (P.J. le B.W.) would like to record his thanks to the Department of Scientific and Industrial Research for financial assistance. 

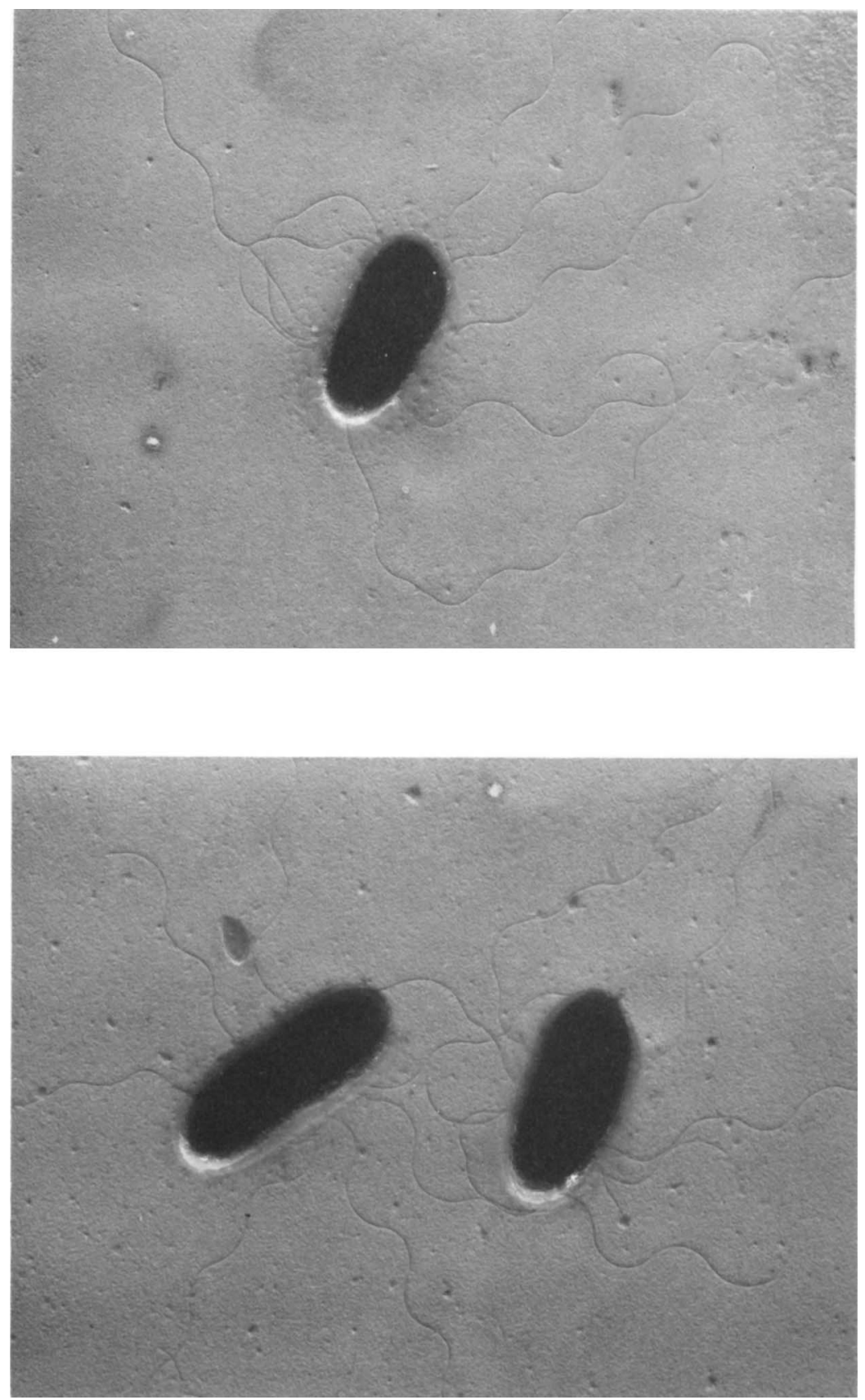


\section{REFERENCES}

AsaI, T. (1934). Taxonomic studies of acetic acid bacteria and allied oxidative bacteria in fruits and a new classification of oxidative bacteria. J. agric. chem. Soc. Japan, 10, 621, 731, 932, 1124. (In Japanese.)

Asai, T. \& Shoda, K. (1958). The taxonomy of Acetobacter and allied oxidative bacteria. J. gen. appl. Microbiol. Japan, 4, 289.

CARr, J. G. \& ShImwell, J. L. (1961). The acetic acid bacteria, 1941-1961. A critical review. Antonie van Leeuwenhoek J. Microbiol. Serol. 27, 386.

DE LEY, J. \& Dochy, R. (1960). On the localisation of oxidase systems in Acetobacter cells. Biochim. biophys. Acta, 40, $27 \%$.

DE LEY, J. (1961). Comparative carbohydrate metabolism and a proposal for a phylogenetic relationship of the acetic acid bacteria. J. gen. Microbiol. 24, 31.

Frateur, J. (1950). Essai sur la Systématique des Acetobacters. La Cellule, 53, 287.

Joubert, J. J., BAyens, W. \& DE LEY, J. (1961). The catabolism of amino acids by acetic acid bacteria. Antonie van Leeurvenhoek J. Microbiol. Serol. 27, 151.

LeIfson, E. (1954). The flagellation and taxonomy of species of Acetobacter. Antonie van Leeurvenhoek J. Microbiol. Serol. 20, 102.

Shimwell, J. L. \& CARr, J. G. (1959). The genus Acetomonas. Antonie van Leeurenhoek J. Microbiol. Serol. 25, 358.

Shimweld, J. L. (1958). Flagellation and taxonomy of Acetobacter and Acetomonas. Antonie van Leeurvenhoek J. Microbiol. Serol. 24, 187.

Stouthamer, A. H. (1960). Koolhydraatstofwisseling van de Azijnzuubacteriën. Thesis, Utrecht.

Stouthamer, A. H. (1961). Glucose and galactose metabolism in Gluconobacter liquefaciens. Biochim. biophys. Acta, 48, 484 .

Stouthamer, A. H. (1962). Energy production in Gluconobacter liquefaciens. Biochim. biophys. Acta, 56, 19.

\section{EXPLANATION OF PLATE}

Gluconobacter liquefaciens. Electron micrographs showing peritrichous flagella. $\times 10,000$. 